\title{
Small bowel transplantation in outbred rats ${ }^{1}$ \\ Transplante de intestino delgado em ratos não-isogênicos
}

\author{
Daniel Reis WaisbergI, André Dong Wong LeeII, Rafael Miyashiro Nunes dos Santos ${ }^{\mathrm{III}}$, Eduardo Kenji Mory ${ }^{\mathrm{III}}$, Anderson Lino \\ Costa $^{\text {IV }}$, Edna Frasson de Souza Monterov, Eleazar Chaib ${ }^{\mathrm{VI}}$, Luis Augusto Carneiro D'Albuquerque ${ }^{\mathrm{VII}}$, Flavio Henrique Ferreira \\ Galvao $^{\text {VIII }}$
}

I'Graduate student, FMUSP, Sao Paulo, Brazil. Helped with technical procedures, collection and processing of study informations, acquisition and interpretation of data, responsible for manuscript writing and English language.

"PhD, Digestive Tract Transplantation Division, Department of Gastroenterology, FMUSP, Sao Paulo, Brazil. Provided guidelines for the surgical interventions, designed the protocol, involved with technical procedures.

IIIResident, Department of Gastroenterology, FMUSP, Sao Paulo, Brazil. Helped with technical procedures, collection and processing of study informations, acquisition and interpretation of data.

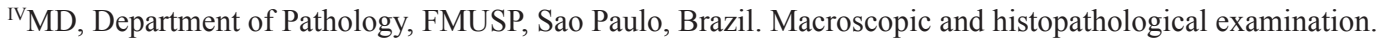

${ }^{v} \mathrm{PhD}$, Associate Professor, Operative Technique and Experimental Surgery Division, Department of Surgery, Federal University of Sao Paulo (UNIFESP), Brazil. Critical revision.

VIPhD, Assistant Professor, Digestive Tract Transplantation Division, Department of Gastroenterology, FMUSP, Sao Paulo, Brazil. Responsible for intellectual and scientific content of the study, supervised all phases of the study, critical revision.

VIIPhD, Chairman and Head, Digestive Tract Transplantation Division, Department of Gastroenterology, FMUSP, Sao Paulo, Brazil. Responsible for intellectual and scientific content of the study, critical revision.

${ }^{V I I I} \mathrm{PhD}$, Digestive Tract Transplantation Division, Department of Gastroenterology, FMUSP, Sao Paulo, Brazil. Responsible for intellectual and scientific content of the study, designed the protocol, involved with technical procedures, acquisition and interpretation of data, responsible for manuscript writing.

\section{ABSTRACT}

PURPOSE: To investigate the clinical evolution of orthotopic small bowel transplantation in outbred rats.

METHODS: Seventy-two outbred Wistar rats weighting from 250 to $300 \mathrm{~g}$ were used as donor and recipient in 36 consecutives ortothopic small intestine transplantation without immunosuppression. The graft was transplanted into the recipient using end-to-side aortic and portacaval microvascular anastomosis. Procedure duration, animal clinical course and survival were evaluated. Survival shorter than four days was considered technical failure. Recipients were sacrificed with signs of severe graft rejection or survival longer than 120 days. Necropsies were performed in all recipients to access histopathological changes in the graft.

RESULTS: Median time for the procedure was 107 minutes. Six recipients (16.7\%) presented technical failure. Twenty-seven recipients were sacrificed due to rejection, being nineteen $(52.7 \%)$ between $7^{\text {th }}$ and $15^{\text {th }}$ postoperative day and eight $(22.2 \%)$ between $34^{\text {th }}$ and $47^{\text {th }}$ postoperative day. Graft histology confirmed severe acute cellular rejection in those recipients. Uneventful evolution and survival longer than 120 days without rejection were observed in three recipients $(8.3 \%)$.

CONCLUSION: Intestinal transplantation in outbred rats without immunosuppressant regiment accomplishes variable clinical evolution.

Keywords: Intestine, Small. Transplantation. Microsurgery. Animals, Outbred Strains. Rats.

\section{RESUMO}

OBJETIVO: Investigar a evolução clínica do transplante de intestino delgado ortotópico em ratos não-isogênicos.

MÉTODOS: Setenta e dois ratos Wistar não-isogênicos, com peso variando entre 250 e $300 \mathrm{~g}$, foram utilizados como doadores e receptores em 36 transplantes ortotópicos de intestino delgado sem regime de imunossupressão. Os enxertos foram implantados nos receptores por meio de anastomose microvascular término-lateral aorta-aorta e porto-cava. A duração do procedimento, evolução clínica dos animais e sobrevida foram avaliados. Sobrevida menor que quatro dias foi considerada falha técnica. Os receptores foram sacrificados quando apresentaram sinais de rejeição grave do enxerto ou sobrevida maior que 120 dias. Necropsias foram realizadas em todos os receptores para avaliar alterações histopatológicas no enxerto. 
RESULTADOS: O tempo médio para o procedimento foi de 107 minutos. Seis receptores (16,7\%) apresentaram falha técnica Vinte e sete receptores $(75 \%)$ foram sacrificados por rejeição sendo dezenove $(52,7 \%)$ entre o $7^{\circ}$ e $15^{\circ}$ dia de pós-operatório e oito $(22,2 \%)$ entre o $34^{\circ}$ e $47^{\circ}$. Análise histopatológica confirmou rejeição celular aguda severa nesses recipientes. Evolução sem complicações e sobrevida maior que 120 dias sem sinais de rejeição foi observada em três receptores $(8,3 \%)$.

CONCLUSÃO: O transplante de intestino delgado ortotópico em ratos Wistar não-isogênicos sem regime de imunossupressão apresenta evolução clínica variada.

Descritores: Intestino Delgado. Transplante. Microcirurgia. Animais não Endogâmicos. Ratos.

\section{Introduction}

Small bowel transplantation (SBT) is a valid treatment for complex intestinal failure; however, its routine clinical use is still limited because of the high incidence of complications ${ }^{1}$. Understanding the physiological and immunological aspects of the transplanted graft is paramount for further progress in this area. Rat models are inexpensive, technically viable and ethically acceptable, thereby being frequently employed in intestinal transplantation research. They are widely used to investigate graft rejection, graft preservation, graft-versus-host disease, and other transplant-related complications ${ }^{2}$.

Monchik and Russel $^{3}$ reported in 1971 the first experimental model of intestinal transplantation in rats, using microvascular anastomoses. Even though their model remains the most popular for intestinal transplantation, it does have some drawbacks and requires skilled microsurgeons to achieve convenient success rates ${ }^{4}$.

Outbred Wistar rat is the customary strain used for research in Brazil and other developing countries. There is a lack of investigations in medical literature assessing the outcome of intestinal transplantation in outbred rats. This study was designed to investigate the clinical evolution of orthotopic SBT in outbred Wistar rats without immunosuppression.

\section{Methods}

This study followed the guidelines of the International Council for Laboratory Animal Science. The study protocol was reviewed and approved by the University of São Paulo, Brazil, institutional ethical committee (CAPPesq number 0358/09). Outbred Wistar rats from the University of Sao Paulo Medical School Animal facility were used in this study.

\section{Animals and experimental design}

Seventy-two male outbred Wistar rats, weighting from 230 to 270 grams, were used as donors and recipients in thirty-six one-step non-auxiliary orthotopic small bowel transplantations. Immunosuppressive regiment was not carried out and the recipients were sacrificed with clinical signs of severe graft rejection or survival longer than four months. Recipient survival shorter than 4 days was considered technical failure.

\section{Intestinal transplantation technique}

Donor operation - after inhalatory induction with isoflurane, rats were anesthetized with subcutaneous administration of ketamine $(30 \mathrm{mg} / \mathrm{kg})$ and xylazine $(30 \mathrm{mg} / \mathrm{kg})$. The abdomen was opened through a large midline incision. The microsurgical technique involves surgical microscope, using magnifying varying from 6 to16x. Rat vascular anatomy from the upper abdomen is shown on Figure 1.

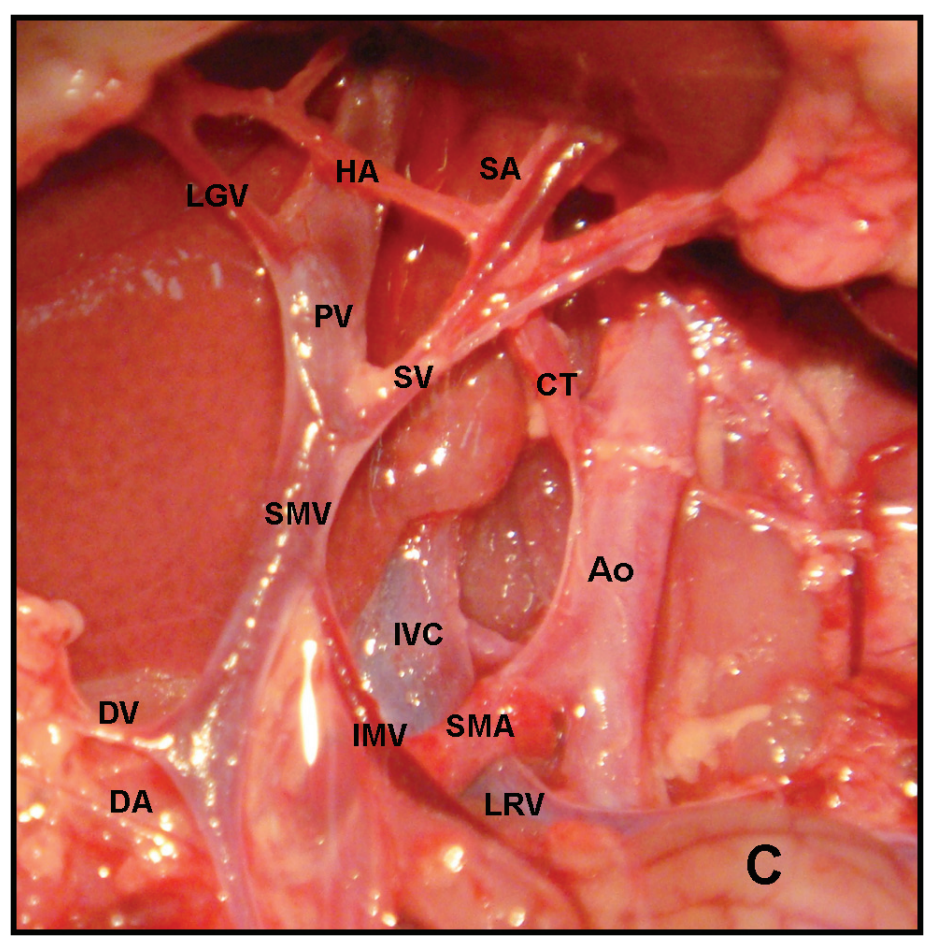

FIGURE 1 - Rat vascular anatomy from the upper abdomen. Ao, abdominal aorta; C, colon; CT, celiac trunk; DA; duodenal artery; DV, duodenal vein; HA, hepatic artery; IMV, inferior mesenteric vein; IVC, inferior vena cava; LGV; left gastric vein; $\mathbf{L R V}$, left renal vein; PV, portal vein; SA, splenic artery; SMA, superior mesenteric artery; SMV, superior mesenteric vein; $\mathbf{S V}$, splenic vein. 
The Trietz ligament was dissected and the graft was wrapped in moistened gauze and positioned to the left side, exposing the retroperitoneum. The aorta was dissected around the emergence of the superior mesenteric artery and the right renal artery was divided. The superior mesenteric vein and portal vein were separated from the pancreas and connective tissues by carefully liberation and section of its tributaries vessels, including, duodenal vessels, ileocecal, right and middle colic veins, splenic vein and left gastric vein. To facilitate this procedure, a HalstedMosquito forceps pulls the stomach and spleen to the upper part of the incision and outside the abdominal wall, and the duodenum is retracted to the right by two others Halsted-Mosquito forceps, forming a "C" shape and exposing the mesoduodenum. The abdominal aorta was dissected around the mesenteric artery, up to the celiac trunk and down to the right renal vessels. We infused $0.3 \mathrm{~mL}$ of Heparin $(5.000 \mathrm{UI} / \mathrm{mL})$ by penile vein. The dissected aorta was clamped below the diaphragm, tied below the mesenteric artery and cut underneath the clamp and the tie, performing an aortomesenteric conduit. The portal vein was cut near hepatic hilum. The small bowel was incised in the proximal jejunum, two centimeters distally from the duodenum, and in the distal ileum, five centimeters proximally from the cecum. The aortomesenteric conduit and the jejunum were cannulated and graft's intravascular and intraluminal content were washed by cold lactated Ringer solution. The graft was removed and placed in a recipient containing $50 \mathrm{~mL}$ of cold lactated Ringer solution at $4^{\circ} \mathrm{C}$ (Figure 2). The clamp in aorta was removed and the animals were sacrificed by exsanguination.

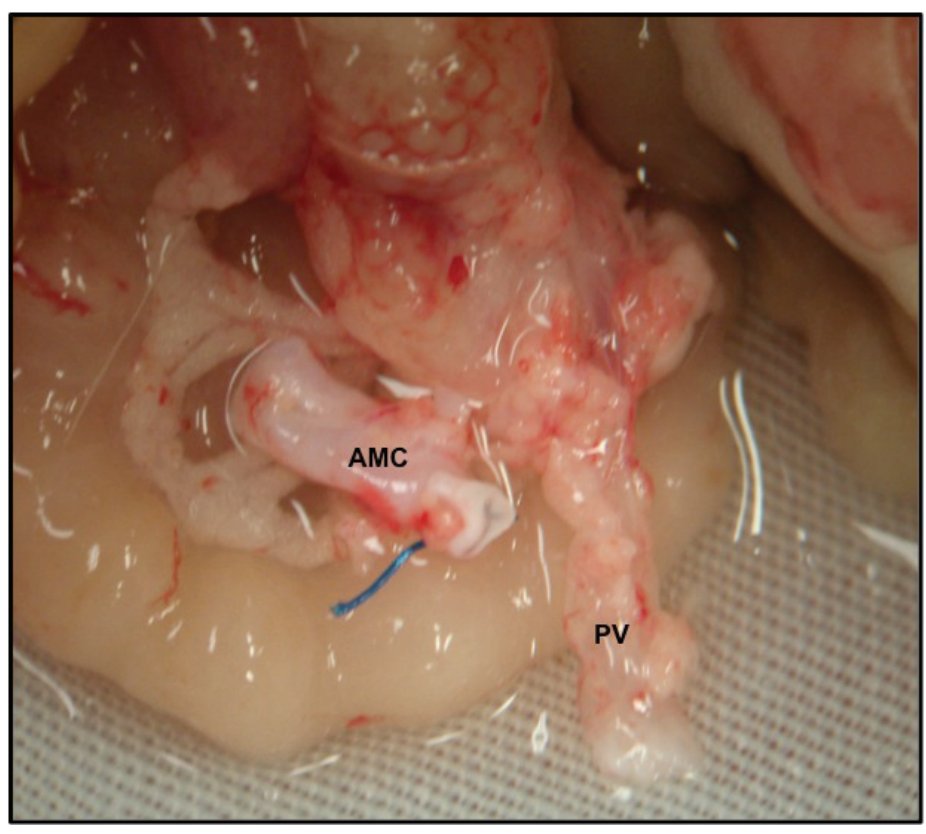

FIGURE 2 - Small bowel graft in preservation solution. AMC, Aortomesenteric conduit; PV, Portal Vein.

\section{Recipient operation}

After the same anesthesia protocol described for the donor, we infused by penile vein ceftriaxone $(50 \mathrm{mg} / \mathrm{kg})$ and metronidazole $(7.5 \mathrm{mg} / \mathrm{kg})$. The abdomen was opened through a large midline laparotomy. Infrarenal aorta and vena cava were dissected. Using a surgical microscope with a magnifying varying from 10 to $25 \mathrm{x}$, a segment of about 15 milimeters of both vessels was cross-clamped and an aortotomy and cavotomy were performed between the clamps. The graft was placed in the recipient's left abdomen. A stitch was done between the donor aortomesenteric conduit angles and the recipient infra-renal aorta angles. A 10-0 nylon end-to-side running suture was performed on the medial side of the anastomosis. Afterwards, the graft was positioned in the recipient's right abdomen and the same suture was applied on the lateral surface, completing the aortic anastomosis (Figure $3 \mathrm{~A})$. The portal vein was anchored to the recipient's infra-renal vena cava by stitches between the angles of those vessels. The medial side of the anastomosis was performed by 10-0 Nylon endto-side running suture from the inside and the lateral one, from the outside (Figure 3B and 3C). The clamps were released and immediate pulsation of the aortomesenteric conduit (Figure 3D) and graft reperfusion were observed (Figure 4). The corresponding recipient's intestine was removed and enteric reconstitution was performed by 7-0 poliglactin end-to-end running suture between the graft and recipient's duodenum and ileum. The abdomen wall and skin were closed by two 4-0 Nylon running sutures.

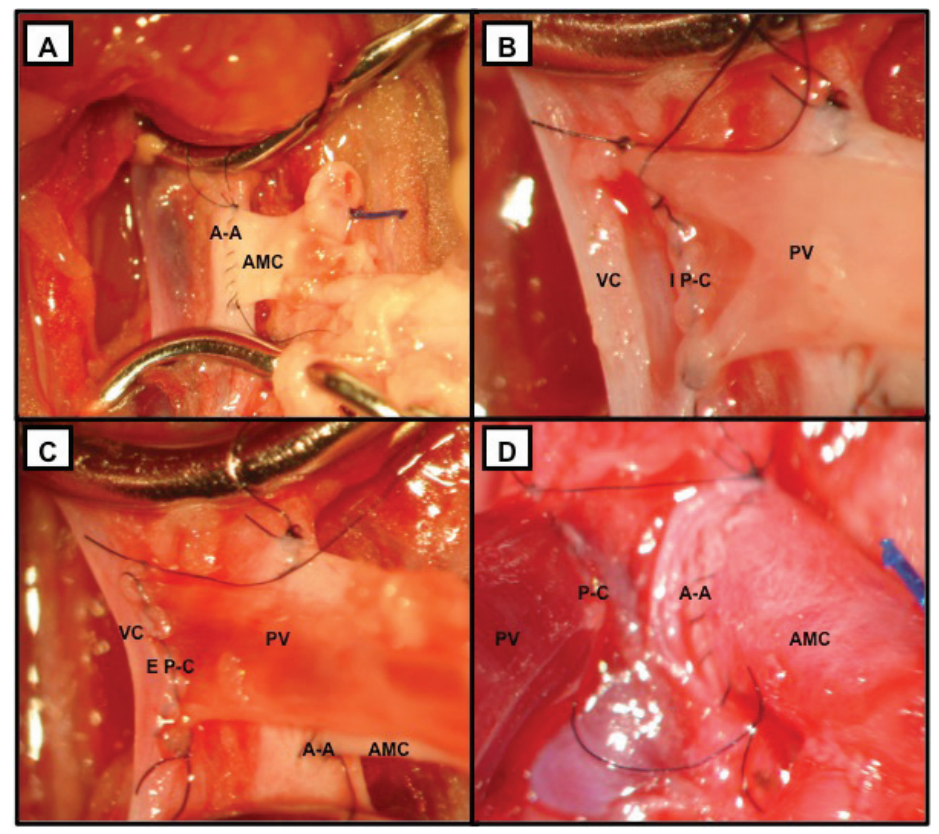

FIGURE 3 -A.Aortic anastomosis (A-A). B. Internal surface of portocaval anastomosis (I P-C). C. External surface of portocaval anastomosis (E P-C). D. Anastomoses after reperfusion. AMC, Aortomesenteric conduit; PV, portal vein; VC, Inferior Vena Cava. 


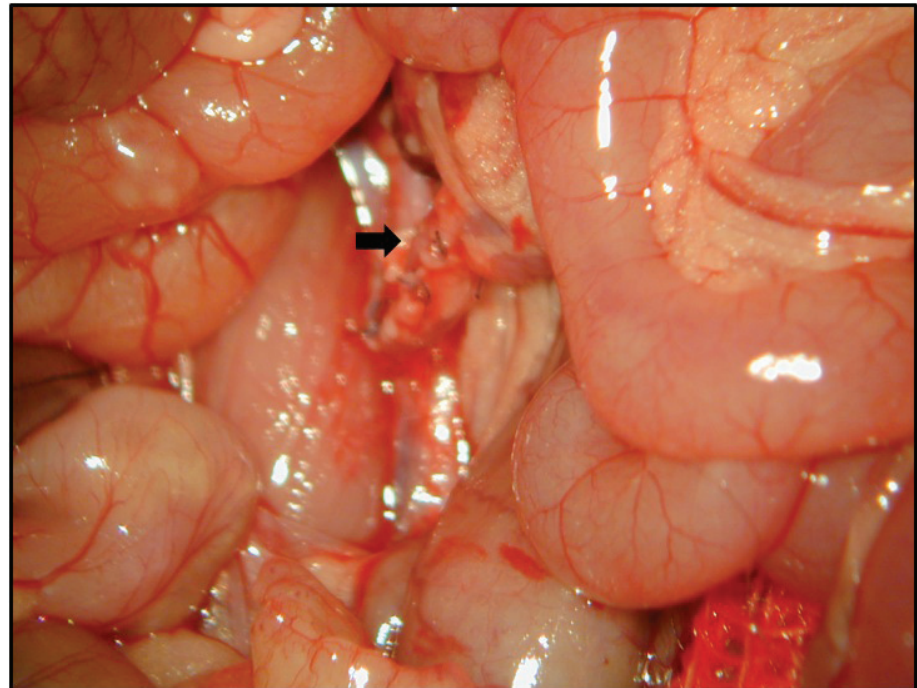

FIGURE 4 - Graft after reperfusion. The arrow points to the aotomesenteric conduit and donor's portal vein.

\section{Clinical follow up}

After the procedure, the animals were confined in lightheated cage and maintained under intensive care until complete anestesic recuperation. Conscious animals were transferred to animal facility. Clinical examination was performed three times a week. Administration of intramuscular ceftriaxone continued until the $3^{\text {rd }}$ post-operative day. Recipients were sacrificed when presenting signs of severe acute rejection (lethargic posture, diarrhea, abdominal distention and more than $30 \%$ of body weight loss), or after four months survival (experimental end point) Before sacrifice, the animals were anesthetized by innalatory administration of isofluorane and wide cross laparotomy was performed to investigate the abdominal cavity. Necropsies were performed to access histopathological changes of the graft.

\section{Histopathologic evaluation of acute rejection}

Tissue obtained was fixed in $10 \%$ buffered formalin. Histological sections of $3 \mu \mathrm{m}$ thickness were obtained from paraffin blocks and stained with hematoxylin-eosin. The degree of acute rejection (mild, moderate and severe) was analyzed as previously described ${ }^{5}$.

\section{Results}

\section{Time of operation procedure}

Mean time for donor surgery was $40 \pm 9 \mathrm{~min}$ and for graft preparation was $6 \pm 3 \mathrm{~min}$. Mean recipient operation time was 57 $\pm 15 \mathrm{~min}$, for arterial anastomosis was $12 \pm 7 \mathrm{~min}$ and for venous anastomosis was $16 \pm 6$ min. Mean graft cold ischemic time was $43 \pm 23$ minutes and mean warm ischemic time was $27 \pm 5 \mathrm{~min}$. Mean total operative time was 107 minutes.

\section{Clinical course and survival}

Six recipients died before $4^{\text {th }}$ post-operative day due to technique failure [microvascular anastomosis thrombosis $(n=3)$, bleeding $(\mathrm{n}=2)$ and ileal anastomosis occlusion $(\mathrm{n}=1)]$. During the first seven post-operative days, all of the remaining 30 recipients lost $5-15 \%$ of their body weight. They started to gain weight between $7^{\text {th }}$ and $10^{\text {th }}$ post-operative days, unless acute rejection occurred. Twenty-seven recipients $(75 \%)$ were sacrified due to rejection [nineteen $(52.7 \%)$ between $7^{\text {th }}$ and $15^{\text {th }}$ post-operative day and eight $(22.2 \%)$ between $34^{\text {th }}$ and $47^{\text {th }}$ post-operative day] Tree animals (8.3\%) were sacrificed after four months survival, without any clinical sign of rejection. None of the recipients presented evidence of graft-versus-host disease.

\section{Autopsy findings}

In the three recipients with four months survival, we observed small amount of abdominal adhesions and graft with normal macroscopic aspect. In the 27 recipients sacrificed with symptoms of rejection, we observed purulent ascites owing to perforation of the Peyer's patch with fecal peritonitis $(n=13)$, diffuse interintestinal adhesions ( $\mathrm{n}=21$ ), diffuse graft inflammation $(n=16)$ and enlarged mesenteric lymph nodes $(n=25)$ (Figure 5).

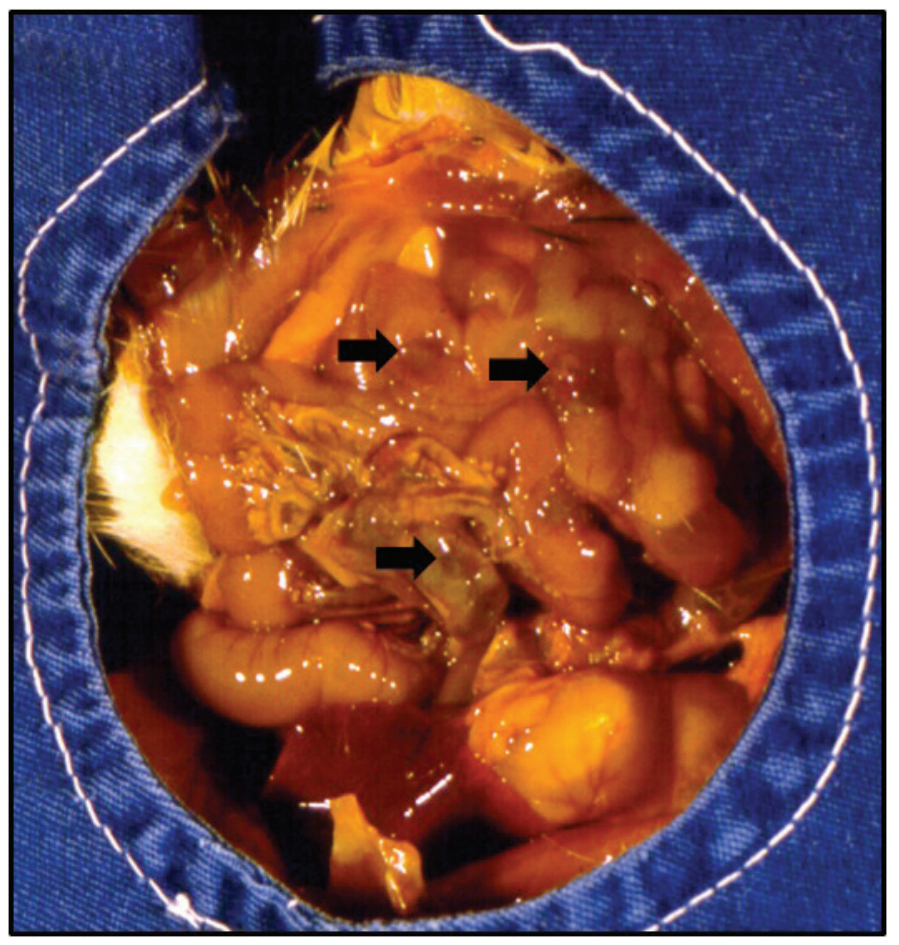

FIGURE 5 - Peritonitis and perforation of Peyer's patches (arrows) found during necropsy of a recipient sacrificed with signs of rejection. 


\section{Histopathological findings}

All recipients sacrificed with symptoms of rejection showed on histopathological analysis severe acute graft rejection. It was characterized by extensive villus blunting, necrotic changes of the superficial mucosa, severe mixed inflammatory cell infiltrate and extensive amount of lymphocytic cryptitis, vasculitis, and occasionally transmural necrosis (Figure 6). Normal appearance of the graft was observed in the three animals with four months survival.

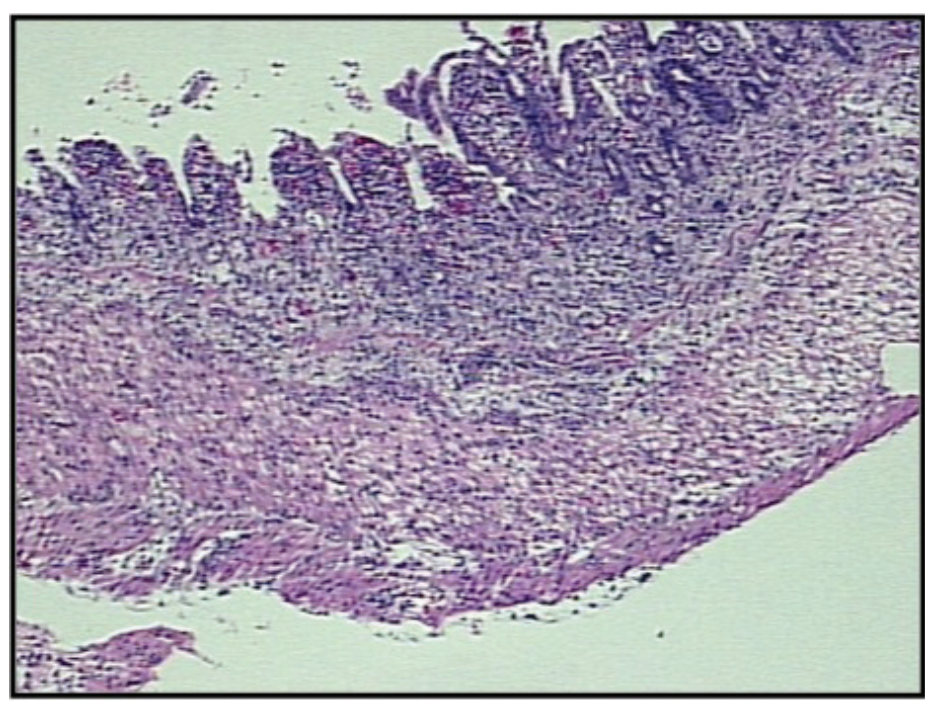

FIGURE 6 - Histological aspect of severe acute cellular rejection in the intestinal graft, with extensive villus blunting and extensive ulceration of villus revetment epithelium. In intestinal mucosa, it was observed destruction of mucosa glands and intense and diffuse inflammatory cell infiltrate in lamina propria. Vasculitis due to inflammatory infiltrate was more prominent in mucosa and submucosa. Edema was observed in submucosa and muscular wall, in addition to apoptotic cells and transmural necrotic focuses (x100 magnification).

\section{Discussion}

Clinical indication of intestinal transplantation has increased and about two thousand cases have been reported in several countries ${ }^{1}$. Nevertheless, intestinal transplantation cumulative mortality is still higher than others solid abdominal organ transplantation (liver and kidney), mainly because of acute and chronic rejection, infection and graft-versus-host disease ${ }^{1}$. Due to its distinctive immunologic and physiologic characteristics, intestinal transplantation is a challenging therapeutic protocol. Thus, experimental research in rats is a relevant instrument to appraise new methods to improve this procedure.

For intestinal transplantation immunology research, positive and negative controls of rejection are fundamental in comparative models ${ }^{2,5}$. Negative control is achieved when the transplantation is performed between rats of the same inbreed strain (isogeneic transplantation). In this situation, investigators are able to evaluate the physiologic consequences of transplantation without the inconvenient interference of rejection ${ }^{2}$. Positive control, on the other hand, is achieved when the transplantation is performed between rats of different inbred strains without immunosuppressant regiment. In this situation, all recipients achieve similar pattern of rejection evolution, dieing in similar post-operative days ${ }^{2}$. In the present study, outbred rats were used and a widely variable clinical evolution of recipients was observed.

We used outbred Wistar rats because this is the usual rat strain used for research in Brazil. Furthermore, there is a lack of reports showing long-term results in the SBT model using outbred rats. The genetic and immunologic patterns of the outbred Wistar rats used in the present investigation are peculiar and the response to SBT was clearly different from those observed in inbred rats. Early death due to strong acute rejection was observed in $52.7 \%$ recipients, which presented an evolution analogous to that observed in allogeneic donor-recipient combination of high immunological response ${ }^{5}$. On the other hand, delayed acute rejection occurred in $22.2 \%$ recipients, an evolution similar to that described for allogeneic donor-recipient combination of low immunological response ${ }^{5}$. Finally, rejection was absent in only $8.3 \%$ recipients, simulating an isogeneic response. Although the varied outcome of rejection in outbred rats may be comparable to that observed in outbred large animals, including humans, these results demonstrate the unpredictability of long-term immunological response in transplantation models using outbred rats. In a previous report of our group ${ }^{6}$, we observed $41.1 \%$ (7 out of 17) of 30 days post-operative survival. These widely variable results corroborate the unpredictability of outbred rats long-term evolution. However, the high incidence of technical failure (20 out of 37 animals died before $3^{\text {rd }}$ post-operative day) and the early experimental end-point (30 days post-operative survival) lessen the significance of our previous results, which actually reflect our initial experience with SBT in rats. With continuous practice, we achieved more acceptable success rates described in the present study.

According to the anatomic position of the intestinal graft, there are basically two surgical models for SBT: heterotopic and orthotopic $^{2}$. In the former, the native small bowel remains intact and the graft is exteriorized by stomas (Figure 7C). This technique allows sequential mucosal biopsies to assess rejection, being useful for immunological studies, and involves a simpler technique, because of the lack of intestinal anastomoses. In the latter (Figure $7 \mathrm{~A})$, the native intestine is removed and replaced in-continuity. 
The graft is exposed to a normal intraluminal environment and, as recipient's survival depends on the efficiency of the graft, death due to rejection provides a well-defined study endpoint. It is also more suitable for preclinical studies.

Donor's portal vein may be anastomosed to the recipient's vena cana (systemic drainage - Figure 7A) or portal vein (portal drainage - Figure 7B). Venous-hand suture anastomosis is a rather difficult technique, because the thin-walled vein may be easily torn and overtightening of the running suture can easily occur, resulting in anastomotic stenosis ${ }^{7}$. Systemic drainage is usually preferred, since hand-sewn end-to-side porto-portal anastomosis is considered to be more challenging and is related to a high incidence of venous thrombosis. Infrarenal vena cava is readily accessible when performing aortic anastomosis, whereas it may be necessary to separate the portal vein from the common bile duct and the hepatic artery to perform the porto-portal anastomosis. Furthermore, even in graft systemic drainage model, alterations in liver function are much less pronounced than in portocaval shunts, with no clinical observable consequences ${ }^{8}$.

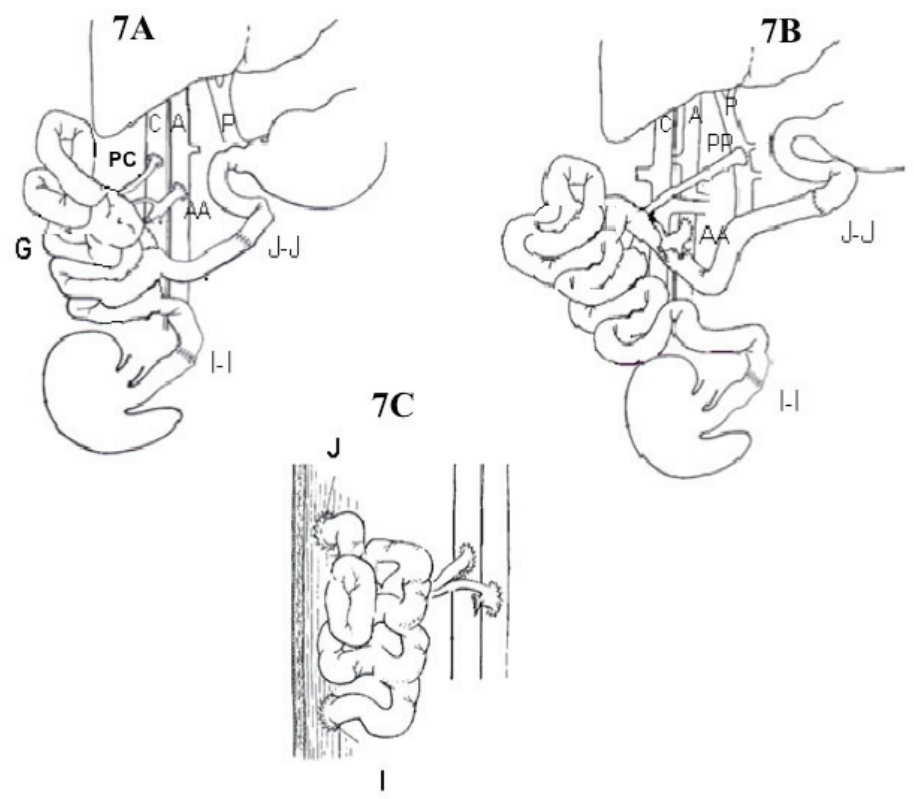

FIGURE 7 - Diagram showing the most used intestinal transplantation techniques in the rat. A. Orthotopic fashion with systemic graft drainage. B. Orthotopic fashion with portal graft drainage. C. Heterotopic fashion. C: Vena cava. A: Aorta. P: Portal vein. G: graft. PC: portocaval anastomosis. AA: Aortic anastomosis. PP: Porto-portal anastomosis. I-I: Ileo-ileal anastomosis. J-J: jejuno-jejunal anastomosis J: Jejunostomy. I: Ileostomy.

The perioperative success rate in orthotopic SBT varies from $46 \%$ to $86 \% \%^{6,9,10}$ and reflects the surgical experience of each group performing SBT in rats. The success rate found in this study was $83.3 \%$, which is comparable to those from literature.
Vascular complications leading to surgical failure reported in literature are $1.3 \%{ }^{9}, 25 \%{ }^{7,11}$ and $40.5 \%^{6}$, thereby the rate found in this series (13.8\%) is acceptable. The present mean arterial microanastomosis time (12min), cold and warm ischemic time (43 and $27 \mathrm{~min}$, respectively) and total procedure time (107min) are also within the range reported in literature (15 to $25 \mathrm{~min}^{7,12} ; 45$ to $67 \mathrm{~min}^{6,10,11}, 25 \mathrm{~min}^{9}$ and 113 to $120 \mathrm{~min}^{9,11}$, respectively). Mean donor operation time in this study (40min) is shorter than found in others studies $\left(57^{12}, 81^{11}\right.$ and $\left.89 \mathrm{~min}^{9}\right)$. The use of the "C-shape" technique to simplify graft removal may explain these findings.

Small bowel transplantation in rats is a complex procedure that requires time-consuming education, mainly due to the use of microvascular anastomosis ${ }^{4}$, especially the venous one, which is a frequent site of thrombosis ${ }^{6,7}$. Various alternative SBT models have been therefore introduced. Wallender et $a l .{ }^{13}$ described a model applying the cuff technique to perform end-to-end anastomoses using the recipient's left renal vessels, which is technically easier and faster to learn. However, this technique has the inconvenient of a left nephrectomy and the decreased blood flow provided by the renal artery limits the graft to $40 \mathrm{~cm}$ of small bowel length 7 . This led to the description of a combined suture and cuff model, which involves hand-sewn end-to-side aortic anastomosis and maintains the cuff venous anastomosis between donor's portal vein and recipient's left renal vein ${ }^{7}$. Our group modified this model by using cuff end-to-end porto-portal anastomosis and adding the cecum and ascending colon to the graft ${ }^{4}$. These technical modifications provide physiologic portal drainage and allow colon transplantation studies. Another alternative model uses the 3-cuff technique, in which two cuffs are placed on a segment of donor's aorta containing the superior mesenteric artery and another one in the recipient's portal vein ${ }^{12}$. However, the cuff persistence in anastomosis may ground foreign body reaction and thrombosis in $40 \%$ of cases $^{14}$, thereby being unsuitable for long-term studies. We then recently introduced a new modification in our model, using cuff-glue sutureless technique to perform the venous anastomosis ${ }^{15}$, which avoids the inconvenient complications of cuff persistence in the anastomosis. The use of these novel techniques may improve the performance of SBT models and amplify research possibilities in transplantation centers worldwide.

\section{Conclusion}

Intestinal transplantation in outbred Wistar rats without immunosuppressant regiment accomplishes variable clinical evolution. Most recipients died due to severe acute graft rejection; however, $8.3 \%$ of recipients did not present rejection and achieved 
long-term survival.

\section{References}

1. Abu-Elmagd KM, Costa G, Bond GJ, Soltys K, Sindhi R, Wu T, Koritsky DA, Schuster B, Martin L, Cruz RJ, Murase N, Zeevi A, Irish W, Ayyash MO, Matarese L, Humar A, Mazariegos G. Five hundred intestinal and multivisceral transplantations at a single center: Major advances with new challenges. Ann Surg. 2009;250:567-81.

2. Nakao A, Tahara K, Inoue S, Tanaka N, Kobayashi E. Experimental models of small intestinal transplantation in rats: orthotopic versus heterotopic model. Acta Med Okayama. 2002;560:69-7.

3. Monchik GJ, Russell PS. Transplantation of small bowel in the rat: technical and immunological considerations. Surgery. 1970;70:693702.

4. Galvao FH, Santos RM, Machado MA, Bacchella T, Machado MC. Simplified rat model of intestinal transplantation. Transplantation. 2005;80:1522-3.

5. Tanabe M, Murase N, Demetris AJ, Hoffman RA, Nakamura K, Fujisaki S, Galvao FH, Todo S, Fung J, Starzl TE. The influence of donor and recipient strain in isolated small bowel transplantation in rats. Transplant Proc. 1994;26:3733-40.

6. Lee AD, Gama-Rodrigues J, Galvao FH, Waitzberg DL. Study of morbidity in orthotopic small intestine transplantation with Wistar rats. Arq Gastroenterol. 2002;39:39-47.

7. Kawabe T, Nakai T, Okuno K, Shindo K, Yasutomi M. Small bowel transplantation in rats using a venous cuff technique. Microsurgery. 1998;18:344-7.

8. Schraut WH, Abraham VS, Lee KK. Portal versus caval venous drainage of small bowel allografts: technical and metabolic consequences. Surgery. 1986;99:193-8.

9. Zhong R, Grant D, Sutherland F, Wang PZ, Chen HF, Lo S, Stiller $\mathrm{C}$, Duff J. Refined technique for intestinal transplantation in the rat. Microsurgery. 1991;12:268-74.

10. Scholten E, Werker PM, Green CJ, Kon M. Experimental orthotopic small bowel transplantation: a revised model. Microsurgery. 1996;17:409-13.

11. Baláz P, Kudla M, Matia I, Fronĕk J, Ryska M. Model of small bowel transplantation with systemic venous drainage in rats. Ann Transplant. 2003;8:36-8.

12. Xue L, Lu Y, Qiu W, Zhou H, Zhang G, Jin Z, Lin M, Chen H, Rui Z, Zheng Y. Surgical experience of refined 3-cuff technique for orthotopic small-bowel transplantation in rat: a report of 270 cases. Am J Surg. 2009;198:110-21.
13. Wallander J, Holtz A, Larsson E, Gerdin B, Lackgren G, Tufverson G. Small-bowel transplantation in the rat with a nonsuture cuff technique. Technical and immunological considerations. Transpl Int. 1988;1:135-9.

14. Nakao A, Ogino Y, Tahara K, Uchida H, Kobayashi E. Orthotopic intestinal transplantation using the cuff method in rats: a histopathological evaluation of the anastomosis. Microsurgery. 2001;21:12-5.

15. Waisberg DR, Galvão FH, Galvão RC, Chaib E, D'Albuquerque LA. Intestinal transplantation using cuff-glue sutureless technique for microanastomosis in rats. Microsurgery. 2011. Epub ahead print.

\section{Correspondence:}

Flávio Henrique Ferreira Galvão

Avenida Doutor Arnaldo, 455/3206

01246-903 São Paulo - SP Brasil

Tel.: (55 11)3061-8319

Fax: (55 11)3061-7270 / 9866-6680

fgalvao@usp.br

Received: May 25, 2011

Review: July 26, 2011

Accepted: August 29, 2011

Conflict of interest: none

Financial source: none

1Research performed at LIM-37, Laboratory of Experimental Transplant Surgery, Division of Digestive Tract Transplantation, Department of Gastroenterology, University of Sao Paulo Medical School (FMUSP), Brazil.

Presented at the XII National Congress on Experimental Surgery of the Brazilian Society for the Development of Research in Surgery-SOBRADPEC 2011 October 26-29, Ribeirao Preto-SP, Brazil. 